\title{
O RECRUTAMENTO POLÍTICO NO PT E NO PFL PARANAENSES NAS ELEIÇÕES DE 2006: SUGESTÕES DE PESQUISA $^{1}$
}

\author{
Renato Monseff Perissinotto ${ }^{2}$ e \\ Bruno Bolognesi ${ }^{3}$
}

\begin{abstract}
Resumo
0 objetivo deste artigo é, num primeiro momento, analisar os estatutos de dois partidos situados em pólos opostos do espectro ideológico, quais sejam, o PT e o PFL (atual Democratas). Com relação a este ponto, nosso objetivo é avaliar o grau de inclusividade que cada um dos referidos partidos prevê no processo de formação de suas listas de candidatos. Num segundo momento, pretendemos analisar os perfis dos candidatos à Assembléia Legislativa e à Câmara dos Deputados dos dois partidos e, por fim, ver em que medida tais perfis se relacionam às regras formais de recrutamento previstas nos estatutos partidários. A hipótese é que o processo formal exerce influência de alguma forma no recrutamento de candidatos e que a oposição ideológica sirva como um aparato explicativo das diferenças entre 0
\end{abstract}

\footnotetext{
${ }^{1}$ Os autores gostariam de agradecer aos pareceristas anônimos de Mediações, cujos comentários melhoraram substancialmente este artigo.

${ }^{2}$ Professor adjunto do Departamento de Ciências Sociais da UFPR, coordenador do Núcleo de Pesquisa em Sociologia Política Brasileira (NUSP) e pesquisador do CNPq.

${ }^{3}$ Doutorando em Ciência Política na UFSCAR, pesquisador do Núcleo de Pesquisa em Sociologia Política Brasileira (NUSP). É bolsista CNPq.
} 
recrutamento nos dois partidos.

Palavras-chave: Recrutamento político. Partido dos Trabalhadores (Paraná). Partido da Frente Liberal (Paraná).

\title{
Political Recruitment in the PT and PFL of Parana IN THE 2006 EleCtions: DiRECTIONS FOR RESEARCH
}

\begin{abstract}
The objective of this article is to analyze the statutes of two opposite parties in the ideological scale: Partido dos Trabalhadores (PT) and Partido da Frente Liberal (PFL, presently DEM - Democrats). With regard to this subject, our objective is to evaluate the extension of inclusiviness that those parties establish in the process of nominating candidates for election. In a second moment, we analyze the profiles of the candidates for the Local Legislative Assembly and for the Federal Chamber of Deputies and inquire on the extent to which these profiles can be related to formal rules. The hypothesis is that the formal process has some influence on the candidate recruitment and that ideological opposition serves as an explicative variable of the differences between the two parties treated here.
\end{abstract}

Keywords: Political Recruitment. Partido dos Trabalhadores (Paraná). Partido da Frente Liberal (Paraná).

\section{ApresentaÇÃo}

$\mathrm{P}$ artindo-se do pressuposto de que o estudo das elites políticas é de fundamental importância para entender plenamente o funcionamento de nossa poliarquia, devemos aceitar também como fundamental o estudo dos processos por meio dos quais os seus membros são selecionados. Ou seja, se estudar as elites políticas é importante, deve sê-lo também o estudo do seu "recrutamento".

Mas o que seria propriamente um estudo sobre recrutamento? Em geral, no Brasil, as pesquisas que se identificam como estudos de recrutamento são, na verdade, análises do perfil sócio-econômico e profissional dos que "chegaram lá", isto é, dos ocupantes dos postos mais importantes do sistema político brasileiró .

${ }^{4}$ A este respeito ver: Nunes (1978); Fleischer (1981); Love (1982); Love e Barickman (1991); Miceli (1991); Marenco dos Santos (1997); Braga (1998); Santos (2000); Bilac (2001); Messenberg (2002); Rodrigues (2002); Rodrigues (2006); Grill (2007); Marenco dos Santos e Serna (2007). 
Estudos de "recrutamento político", no entanto, precisam analisar todos os filtros que configuram o processo seletivo de uma elite política. Nesse sentido, não é suficiente apresentar um perfil dos vitoriosos e, a partir de suas características, produzir inferências sobre quais grupos sociais são prejudicados ou privilegiados no longo caminho até as posições de elite. Um verdadeiro estudo de recrutamento deve dar conta não apenas das características dos eleitos, mas também das características dos membros dos partidos políticos, dos que buscam ser candidatos e dos que efetivamente são indicados como tal, comparando-as com os atributos da população em geral. Somente assim é que poderemos acompanhar, passo a passo, o processo que seleciona os que, por fim, ocuparão os postos de elite e somente assim poderemos ver quais grupos sociais simplesmente não se lançam na atividade política, quais grupos sociais buscam a carreira política, mas são dela alijados, e quais se encontram sobre-representados na elite política (NORRIS, 1997, em especial cap. 9).

A literatura internacional sobre recrutamento das elites políticas nas democracias tem sugerido que a análise deve começar pelo estudo do processo seletivo dentro dos partidos políticos, já que essas seriam as principais instituições por meio das quais teria início o processo de recrutamento. Nos partidos ocorreria a "filtragem" por meio da qual o amplo universo de "selecionáveis" seria reduzido, pelos "seletores" partidários, a um universo bem menor de aspirantes e candidatos. Essas instituições seriam, assim, os principais "canais" ou as principais "avenidas" de acesso às posições de elite (PUTNAM, 1976; GIDDENS, 1974). No Brasil, este tipo de estudo se faz ainda mais premente, já que aqui, como se sabe, estar filiado a um partido é condição sine qua non para candidatar-se a um cargo eletivo. Saber quem são e como operam as minorias organizadas que controlam o processo seletivo dentro dos partidos parece-nos fundamental para identificar a natureza do leque de opções colocado à disposição do eleitorado e, por conseguinte, o tipo de elite política que finalmente será "escolhida" pelo eleitor para operar o sistema político (SIAVELIS \& MORGENSTERN, 2004).

Este artigo pretende ser uma pequena contribuição para o estudo do processo de recrutamento nos partidos políticos. Ele está estruturado da seguinte maneira: na primeira parte, faremos uma análise dos estatutos partidários do PT e do PFL paranaenses a fim de identificar o grau de inclusividade de cada um desses documentos; a segunda parte dedica-se a uma análise do perfil do universo dos candidatos dos dois partidos; a terceira parte repete a análise anterior para 0 universo de eleitos; na quarta parte analisamos o impacto que algumas variáveis 
produzem sob as chances de um candidato ser ou não eleito. Ao longo de todo o artigo procuramos relacionar as características dos estatutos com os dados sobre perfil de candidatos e eleitos. Em função disso, uma aparente ambigüidade se fará presente no estudo da "inclusividade" dos partidos analisados neste texto. Em determinados momentos do artigo, lançando mão da análise dos estatutos, tratamos a inclusividade como algo relativo à estrutura organizacional dos partidos políticos; em outros momentos, ela aparece como uma característica sociológica referente à origem social de seus candidatos e eleitos. Essa "ambigüidade", portanto, é o reflexo de nossa tentativa de vincular características estatutárias e formais a características substantivas e sociais no processo de recrutamento político dentro dos partidos.

Estudos sobre recrutamento político justificam-se porque se, por um lado, o contexto institucional é inegavelmente importante para explicar os outputs políticos, por outro, pensamos que a natureza dos atores politicamente relevantes que "operam" as instituições também deve ser levada em consideração para uma plena compreensão do funcionamento do sistema político.

\section{RECRUTAMENTO FORMAL: ANÁLISE DOS ESTATUTOS DO PT E PFL 5 .}

A análise dos estatutos partidários tem sido feita com pouca frequêencia pela Ciência Política, tanto brasileira como internacional, sob o argumento de que se constituem em meros formalismos que, de fato, não expressam o que acontece na prática intra e extra-partidária (MICHELS, 2001; PANEBIANCO 2001; RANNEY, 1965). Por essa razão, são poucas as pesquisas que têm como objetivo analisar os estatutos dos partidos políticos e submetê-los à prova empírica. No Brasil, apenas alguns autores se esforçaram no sentido de situar os estatutos como dimensão importante da organização partidária ${ }^{6}$, como, por exemplo, Maria Luzia Miranda

\footnotetext{
${ }^{5}$ No momento da coleta dos dados, o partido hoje denominado Democratas (DEM) ainda possuía o nome de Partido da Frente Liberal (PFL).

${ }^{6}$ Com relação a este ponto, vale dizer que os membros de partido, ao serem confrontados com situações de conflito na vida política, recorrem ao estatuto do partido para ter seus direitos assegurados, lançando mão, portanto, das regras formais para a solução dos embates intrapartidários. Essa informação foi obtida através de entrevistas com os membros da executiva dos partidos. Vale dizer, porém, que se não devemos incorrer no erro de menosprezar a eficácia dos
} 
Álvares e Maria do Socorro Sousa Braga.

A hipótese deste artigo é que os estatutos de partido são mais do que meras formalidades. Ao contrário, acreditamos que o estatuto de um partido afeta 0 perfil dos seus candidatos ${ }^{7}$. Para sermos mais específicos, pretendemos saber se estatutos mais inclusivos no que diz respeito à participação dos eleitores, filiados e militantes produzem também universo de candidatos mais inclusivo. Para realizar a pesquisa, escolhemos dois partidos que ocupam posições opostas no espectro ideológico do Paraná, a saber, o Partido dos Trabalhadores (PT) e o Partido da Frente Liberal $(\mathrm{PFL})^{8}$. Vale observar que analisamos exclusivamente os candidatos e eleitos a cargos de deputado estadual e federal nas eleições de 2006.

Tendo como fio condutor de nossa análise o eixo inclusividade/exclusão, procuraremos identificar em cada estatuto as principais medidas previstas que podem indicar um perfil mais ou menos inclusivo das cartas partidárias. A fim de realizar esse objetivo, lançaremos mão das importantes contribuições de alguns autores, como Hazan (2002) e élvares (2006), por exemplo. Segundo esses autores, a análise da inclusividade dos estatutos partidários deve estar atenta a variáveis tais como a organização do partido, a forma de escolha dos candidatos, a dimensão ideológica, as disposições eleitorais, dentre outras. Neste artigo, consideramos apenas a escolha de candidatos por ser essa uma das funções centrais dos partidos nos sistemas políticos democráticos. Alguns autores chegam mesmo a afirmar que a escolha de candidatos não é apenas uma dentre outras atividades do partido, mas sua única função nas democracias contemporâneas (GALLAGHER \& MARSH, 1988).

estatutos quanto à definição da dinâmica da organização partidária, não devemos também cometer o pecado oposto, qual seja, o de menosprezar o impacto dos procedimentos informais sobre a vida interna dos partidos políticos. No entanto, um estudo desses procedimentos, inescapavelmente qualitativo, escapa aos objetivos iniciais da presente pesquisa.

${ }^{7}$ Neste paper estamos trabalhando apenas com a seleção de candidatos a deputado estadual e federal no estado do Paraná. As disposições para cargos majoritários e suas formas de seleção podem diferenciar dos cargos legislativos nos estatutos partidários.

${ }^{8}$ A localização dos dois partidos nos extremos do espectro ideológico é algo, certamente, passível de debate. Os objetivos deste texto não permitem, entretanto, avançar nessa discussão. Em defesa desse pressuposto, observe-se apenas que se trata de um lugar comum na literatura sobre partidos políticos no Brasil.

O Recrutamento Político no PT e no PFL paranaenses nas eleições ... 


\section{Critérios de inclusividade}

Para a análise do grau de inclusividade dos estatutos do PT e do PFL quanto ao processo de escolha de candidatos, utilizaremos a contribuição de Reuven Hazan. 0 autor elabora uma escala de inclusividade que identifica variáveis que podem ou não estar presentes na vida de qualquer partido político, escala essa que serve como um tipo ideal para classificação dos estatutos de partido. Além dele, Braga \& Praça (2007) apresentam algumas sugestões que também serão incorporadas à nossa análise. Com base nesses autores, chegamos ao seguinte conjunto de questões que devem ser formuladas ao nosso objeto de análise: i) quais as exigência legais para uma pessoa se lançar como candidato a deputado federal e estadual no Brasil?; ii) quais critérios os partidos analisados utilizam para definir quem pode se filiar à organização?; iii) quais critérios o partido estabelece para definir quem pode se lançar como candidato a deputado federal ou estadual?; e iv) quem (que agentes e instâncias partidárias) define a lista de candidatos do partido?A resposta a essas questões será dada a partir da análise dos estatutos do PT e do PFL, o que nos permitirá produzir um índice de inclusividade partidária quanto à amplitude da participação no processo de recrutamento de candidatos em ambos os partidos.

Para a quantificação do estatuto partidário adotamos o seguinte procedimento metodológico. As variáveis elencadas pelas questões apresentadas no parágrafo anterior foram situadas num eixo de inclusividade/exclusão. 0 pólo extremo da inclusividade descreve uma situação ideal em que qualquer cidadão, respeitado os limites legais de cada país, pode se filiar livremente ao partido, qualquer filiado pode se lançar como candidato e todos os eleitores podem participar da definição da lista de candidatos do partido. No outro extremo do eixo, também ideal, haveria fortes restrições ao direito de filiação e o direito de formular a lista de candidatos do partido estaria fortemente concentrado nas mãos de alguns poucos líderes partidários, quando não nas mãos de uma única liderança.

Valendo-nos desses critérios, adotamos o seguinte procedimento: quando um partido é mais inclusivo do que o outro em relação a uma dada variável, ele recebe o valor "1", ficando o outro partido, menos inclusivo, com o valor "0". Do ponto de vista prático, isso quer dizer que " 1 " representa a presença, no interior do partido analisado, de determinados procedimentos mais inclusivos de escolha de candidatos, procedimentos esses ausentes no outro partido. Vejamos isso para cada uma daquelas questões elencadas acima. Ao final deste item, apresentaremos uma tabela que sintetiza as informações quantitativamente. 
(i) Determinações legais para ser candidato no Brasil

No Brasil, as exigências legais para ser candidato a cargo eletivo são as mesmas em todo o território nacional, a saber: possuir nacionalidade brasileira, gozar do pleno exercício dos direitos políticos, estar inscrito no alistamento eleitoral, ter domicílio eleitoral na circunscrição pela qual se candidata e, por fim, ser filiado a algum partido político. A exigência de idade mínima varia de acordo com o cargo almejado. Ainda que a lei, em função de suas restrições, funcione como um primeiro filtro no recrutamento de candidatos, este filtro assume características idênticas para todos os partidos. Ou seja, não é a partir da legislação eleitoral que podemos diferenciar o grau de inclusividade do processo de recrutamento de candidatos nos partidos analisados.

(ii) Quem pode se filiar aos partidos

No Brasil, as exigências legais para a filiação são as mesmas para qualquer partido. No entanto, a comparação dos estatutos dos partidos analisados revela importantes diferenças. 0 PFL simplesmente acata o que a lei diz, ou seja, qualquer pessoa maior de 16 anos, em pleno gozo de seus direitos políticos e com domicílio eleitoral coincidente com o do partido pode se filiar, aceitando, por meio do ato de filiação, as normas estabelecidas no programa estatutário do partido ${ }^{9}$. Mesmo no que concerne aos direitos e deveres o PFL não prevê nenhuma exigência aos filiados.

Já no PT, as exigências quanto à filiação são maiores. 0 artigo $14^{010} \mathrm{do}$ capítulo V da carta do partido revela exigências tais como: "combater todas as manifestações de discriminação"; contribuir financeiramente com o partido'; "renunciar ao mandato eletivo no caso de desligamento do Partido". Ou seja, o partido apresenta uma carga maior de exigências a que o filiado deve se submeter

${ }^{9} \mathrm{Cfe}$. Art. $7^{\circ}$. do Estatuto do Partido da Frente Liberal.

${ }^{10} 0$ artigo referido cita extensivamente as disposições as quais os novos filiados devem se submeter dentro e fora da vida partidária, são elas: participar das atividades do Partido, difundir idéias e propostas partidárias; manter a conduta compatível com os princípios éticos do Partido; acatar e cumprir as decisões partidárias; combater todas as manifestações de discriminação em relação à etnia, aos portadores de deficiência física, aos idosos, ou qualquer outra forma de discriminação social, de gênero, de orientação sexual, de cor ou raça, idade ou religião; contribuir financeiramente nos termos do Estatuto e participar das campanhas de arrecadação de fundos do Partido; votar nos candidatos indicados e participar das campanhas aprovadas nas instâncias partidárias; comparecer, quando convocado, para elucidar fatos em procedimentos disciplinares; emitir voto sobre questões submetidas pelas instâncias de direção e renunciar ao mandato eletivo no caso de desligamento do Partido. 
caso queira ingressar na organização. Constata-se, portanto, no que diz respeito à filiação, que o PFL é mais inclusivo que o PT.

(iii) Quem pode ser candidato

Neste caso, devemos levar em conta tanto o aspecto legal exógeno ao partido quanto aquilo que é previsto internamente. Como já dissemos anteriormente, as condições legais são equivalentes para todos os partidos no Brasil. Ambos os partidos afirmam que qualquer indivíduo filiado, desde que cumpra o tempo de filiação previsto legalmente, pode lançar-se como candidato. Os estatutos do PT e do PFL igualam-se nesse ponto. Veremos mais adiante, porém, que para os casos em análise neste artigo, o perfil de candidatos e eleitos é radicalmente diferente nos dois partidos.

(iv) Quem seleciona os candidatos

A principal diferença entre os dois partidos se revela quando analisamos quem escolhe os candidatos. Nem no PT nem no PFL o estatuto prevê que a escolha de candidatos legislativos se dê por todo o eleitorado (cidadãos), como acontece em alguns estados norte-americanos com as prévias. Assim, PT e PFL apresentaram ausência desta medida de inclusão e obtiveram nota 0.0 mesmo ocorre com a segunda etapa do processo de seleção. Nenhum dos partidos aqui comparados apresentou formas de escolha por meio de seus filiados para a seleção de candidatos aos cargos de deputado federal ou estadual ${ }^{11}$. A seleção por órgão colegiado é a última variável de inclusão que temos em nossa escala. É a última oportunidade que o partido tem para que suas bases se manifestem com alguma medida de representatividade. A seleção por órgão executivo ou por liderança partidária se restringe aos altos escalões do partido e exclui a participação da base que o compõe.

Nesse sentido apenas o PT possui seleção de candidatos por órgão colegiado. 0 partido promove a eleição de delegados que representarão seus filiados na convenção do partido ${ }^{12}$. No PFL, a seleção é realizada por instância superior, tendo como selecionador previsto no estatuto os "convencionais". Aparentemente, portanto, os partidos são próximos neste quesito segundo seus estatutos.

${ }^{11}$ O PT apresenta a participação dos filiados para a escolha de cargos executivos. Porém, deixaremos isto para outro momento, tendo em vista que na parte final deste texto abordaremos a relação entre estatuto partidário e o perfil dos candidatos apenas no que diz respeito aos cargos de deputado estadual e federal.

${ }^{12}$ Tanto no PT quanto no PFL são as convenções as instâncias responsáveis formalmente pela escolha de candidatos ao legislativo. Esta é uma exigência legal do TSE. Lei de eleições n 9.504/97. 
No PT, os militantes elegem, por meio do voto direto, delegados responsáveis por representá-los na convenção do partido, que, por sua vez, são responsáveis pela escolha dos candidatos a legislativo. Não é vedada à participação da base no processo de escolha de candidatos. Na verdade, ela é até estimulada. 0 PT dispõe de um procedimento que chamam de PED, Processo de Eleição Direta, onde cada militante escolhe em seus municípios ou zonas o delegado que irá representá-lo na escolha de candidatos ou na chapa eleitoral. Esse dispositivo está previsto no artigo 35 do estatuto do Partido dos Trabalhadores.

Já o PFL deixa claro no artigo 26 de seu estatuto que a escolha de candidatosé realizada somente com o aval dos convencionais. Estes, que controlam a convenção estadual, responsável pela escolha de candidatos a deputado, devem ser membros do diretório regional ou ocupantes de cargo eletivo estadual, sendo permitido o voto cumulativo. É vetada a composição da mesa de convencionais por vereadores. Existem ainda os delegados que também têm direito de voto na convenção e são escolhidos a partir da seguinte fórmula: cada município tem direito a um delegado (independente da representatividade do município) e mais outro delegado a cada 2.500 votos que o partido obteve na última eleição no mesmo município. A proporção é limitada ao número de 70 delegados por município com mais de 1 milhão de habitantes. A escolha de candidatos é realizada por chapas, que são apresentadas apenas para que os delegados e convencionais ratifiquem as escolhas prévias do partido ${ }^{13}$. Em nenhum momento do estatuto observamos a possibilidade de voto transferível direto. Ou seja, o militante fica também alijado do processo de escolha dos delegados. Destarte, o PFL não inclui em seu processo de seleção de delegados e convencionais a participação direta do filiado, deixando a cargo das executivas do partido e das instâncias burocráticas a escolha de candidatos ao legislativo.

Em suma, a diferença entre o PT e o PFL quanto a este ponto está posta pela análise que Rahat e Hazan (2001) propõem: o primeiro possui um método de seleção que conta com uma agência partidária eleita, enquanto os Liberais possuem, previsto em seu estatuto, uma agência partidária não eleita para a formação das convenções que selecionarão os candidatos. Isso coloca o PT mais próximo do pólo inclusivo e o PFL no ponto escalar mais distante deste pólo ${ }^{14}$. A

\footnotetext{
${ }^{13}$ Além disso, a Mesa Diretora da Convenção Estadual é a responsável direta pela escolha de candidatos caso não haja quorum qualificado ou caso alguma chapa não atinja $80 \%$ do voto dos delegados.

${ }^{14}$ Com relação a essa afirmação, poder-se-ia objetar que depositar a escolha de candidatos num órgão colegiado em grande parte formado por indivíduos sufragados nas urnas, como é o caso do PFL, seria mais democrático, já que o universo de eleitores é muito mais amplo do que o universo

O ReCrutamento Político no PT e no PFL paranaenses nas Eleições ... 
tabela 1 sintetiza as informações apresentadas acima.

\section{TABela 01 - Grau de INCLUSIVIDAde PARTIDÁRIA SEGUNDO OS ESTATUTOS}

\begin{tabular}{ccccccccc}
\hline & $\begin{array}{c}\text { Exigências } \\
\text { Legais para } \\
\text { Candida- } \\
\text { tura }\end{array}$ & $\begin{array}{c}\text { Exigên- } \\
\text { cias } \\
\text { para } \\
\text { Filiação }\end{array}$ & $\begin{array}{c}\text { Exigência } \\
\text { Partidárias } \\
\text { para Can- } \\
\text { didatura }\end{array}$ & $\begin{array}{c}\text { Seleção } \\
\text { pelo } \\
\text { Eleito- } \\
\text { rado }\end{array}$ & $\begin{array}{c}\text { Sele- } \\
\text { ção } \\
\text { pelos } \\
\text { Filiados }\end{array}$ & $\begin{array}{c}\text { Sele- } \\
\text { ção por } \\
\text { Cole- } \\
\text { giado }\end{array}$ & $\begin{array}{c}\text { Não } \\
\text { Seleção } \\
\text { por Exe- } \\
\text { cutiva }\end{array}$ & $\begin{array}{c}\text { Não } \\
\text { Seleção } \\
\text { por Lide- } \\
\text { rança }\end{array}$ \\
PT & 0 & 0 & 1 & 0 & 0 & 1 & 1 & 1 \\
PFL & 0 & 1 & 1 & 0 & 0 & 0 & 0 & 1 \\
\hline
\end{tabular}

Fonte: estatutos do PT e do PFL e Marenco dos Santos \& Serna (2007).

Como podemos ver, o estatuto do Partido dos Trabalhadores apresenta um índice final (de somatório 4) de inclusividade maior do que o estatuto do Partido da Frente Liberal (de somatório 3). Este índice, lembremos, reflete apenas a análise do estatuto dos partidos. Nas seções seguintes examinaremos o perfil dos candidatos e eleitos dos dois partidos em questão e procuraremos estabelecer alguma relação entre as características dos estatutos analisados neste item e as diferenças entre PT e PFL no que diz respeito àqueles dois universos. Vale observar que por ora apresentamos apenas um ensaio de interpretação dos dados coletados.

\section{UM PERFIL SOCIAL DOS CANDIDATOS DO PT E DO PFL: GÊNERO, OCUPAÇÃO E EDUCAÇÃO}

Uma das formas de avaliar o impacto do caráter mais ou menos inclusivo dos estatutos partidários é analisar o perfil do universo dos candidatos segundo seus atributos sociais. No nosso caso, trabalharemos apenas com as seguintes variáveis: gênero, ocupação e escolaridade. Estas variáveis são algumas das mais importantes para os estudos de recrutamento e estão presentes na maior parte das pesquisas sobre o tema (NORRIS e LOVENDUSKI, 1995, p. 9-10). Assim,

de filiados ao partido. No entanto, três observações seriam necessárias quanto a este ponto: primeiramente, os políticos recebem votos dos eleitores para atuarem no Parlamento e não para definirem o leque de candidatos do partido; segundo, a esmagadora maioria dos eleitores desses indivíduos não tem qualquer relação com o seu partido e, não raro, como se sabe, nem sequer têm conhecimento da organização partidária a que pertencem seus candidatos; por fim, seria um tanto quanto curioso definir uma organização como mais ou menos inclusiva a partir procedimentos exteriores a ela. 
pretendemos saber se o PT, por ter estatuto mais inclusivo, tem um universo de candidatos com um perfil social também mais inclusivo.

0 que podemos perceber pelos dados das tabelas 2 e 3 apresentadas abaixo é que os dois partidos não se diferem substancialmente quanto ao gênero e à escolaridade de seus candidatos. Com relação à quantidade de mulheres que se lançam como candidatas, PT e PFL são praticamente idênticos. Com relação à escolaridade, o PT é um pouco mais inclusivo na medida em que lança alguns candidatos que têm apenas o ensino fundamental (incompleto e completo) ${ }^{15}$. De qualquer forma, os testes de associação revelaram que não há qualquer correlação estatisticamente significativa entre 0 gênero e a escolaridade dos candidatos e os partidos a que se filiam.

\section{Tabela 2 - Partido Político e sexo dos Candidatos}

\begin{tabular}{lccc}
\hline & Sexo & & Total \\
\hline PT & Masculino & Feminino & \\
PFL & $91 \%$ & $9 \%$ & $100 \%$ \\
& $90,90 \%$ & $9,10 \%$ & $100 \%$ \\
\hline
\end{tabular}

Fonte: TSE e Núcleo de Pesquisa em Sociologia Política Brasileira - NUSP/UFPR

\section{Tabela 3 - Partido político e nível de escolaridade DOS CANDIDATOS}

\begin{tabular}{lccccccc}
\hline & & \multicolumn{2}{c}{ Escolaridade } & & Total \\
& $\begin{array}{c}\text { Ensino } \\
\text { Fundamental } \\
\text { Incompleto }\end{array}$ & $\begin{array}{c}\text { Ensino } \\
\text { Fundamental } \\
\text { Completo }\end{array}$ & $\begin{array}{c}\text { Ensino } \\
\text { Médio } \\
\text { Incompleto }\end{array}$ & $\begin{array}{c}\text { Ensino } \\
\text { Médio } \\
\text { Completo }\end{array}$ & $\begin{array}{c}\text { Ensino } \\
\text { Superior } \\
\text { Incompleto }\end{array}$ & $\begin{array}{c}\text { Ensino } \\
\text { Cuperior } \\
\text { Completo }\end{array}$ & \\
PT & $6 \%$ & $4,50 \%$ & $4,50 \%$ & $17,90 \%$ & $9 \%$ & $58,20 \%$ & $100 \%$ \\
\hline PFL & $\mathrm{x}$ & $\mathrm{x}$ & $3 \%$ & $15,20 \%$ & $18,20 \%$ & $63,60 \%$ & $100 \%$ \\
\hline Total & $4 \%$ & $3 \%$ & $4 \%$ & $17 \%$ & $12 \%$ & $60 \%$ & $100 \%$ \\
\hline
\end{tabular}

Fonte: TSE e NUSP

${ }^{15}$ É claro que a análise do grau de "inclusividade" ou de "exclusão" quanto às variáveis aqui analisadas (gênero, ocupação e escolaridade) pressupõe uma comparação com a população economicamente ativa do país. Em função dos limites deste texto não faremos essa comparação. Entretanto, é plausível supor que um partido cujos candidatos sejam majoritariamente formados por portadores de diplomas de cursos superior seja menos inclusivo do que outro que abre espaço para candidatos com capital escolar mais baixo, já que este segundo grupo é bem mais extenso na população economicamente ativa do que o primeiro. 
A situação se revela diferente quando cruzamos os partidos com os dados sobre ocupação, cruzamento este que se mostra estatisticamente significativo ${ }^{16}$. Como se percebe pelos dados da tabela 4, o PT paranaense é, no caso dos que pleiteavam uma vaga a deputado estadual e federal em 2006, fundamentalmente um partido que lança como candidatos professores do ensino superior, trabalhadores da educação e políticos profissionais. 0 PFL, por sua vez, é um partido cujos candidatos são majoritariamente advogados, empresários, produtores agropecuários e políticos profissionais.

É interessante observar ainda que tanto para o PT quanto para o PFL é importante a quantidade de candidatos que se declaram como políticos. Entretanto, impressiona o peso dessa categoria entre os candidatos do Partido dos Trabalhadores. Esse dado parece sugerir que o PT se constitui numa organização que demanda a profissionalização política e, por via de conseqüência, a dedicação integral ao partido, como um dos critérios mais importantes para que uma pessoa possa sair como candidata ao cargo de deputado (estadual ou federal) pelo partido. Este dado vai ao encontro dos estudos produzidos por André Marenco dos Santos sobre lealdades partidárias e recrutamento endógeno, que se revela importante também no caso do PT paranaense.

De fato, em geral, a literatura sociológica sobre os partidos políticos aponta para uma maior dependência frente à organização naqueles partidos que recrutam indivíduos de estratos sociais mais baixos e cuja ascensão política passa necessariamente por uma vida dedicada às lides organizacionais. Ao contrário, portanto, daquilo que Duverger chamou de partido de quadros, nos quais o objetivo é reunir pessoas ilustres para preparar eleições, conduzi-las e manter contato com os candidatos; pessoas influentes, cujo nome, prestígio ou brilho servirão de caução ao candidato e lhe granjearão votos; pessoas dotadas de conhecimentos técnicos, versadas na arte de manejar os eleitores e de organizar uma campanha e pessoas com recursos financeiros (1987, p. 100).

Essa situação, aliás, como recorda Panebianco (2005, p. 61-64), pode explicar o caráter mais estruturado do Partido dos Trabalhadores, no sentido de possuir uma burocracia partidária mais sólida e um controle maior sobre 0 processo de filiação e indicação de candidato, ainda que este último procedimento

\footnotetext{
${ }^{16}$ Para o cruzamento entre partido político e ocupação utilizamos o coeficiente de contingência, que é uma medida de associação para duas variáveis nominais. 0 cruzamento resultou num sig $=0,001$ e o valor do coeficiente foi de 0,56 .
} 
seja mais inclusivo ${ }^{17}$. No caso do Partido dos Trabalhadores, é plausível supor que seus membros obtêm no interior do partido recursos que eles não podem obter facilmente em qualquer outro lugar. Em função disso, dedicam-se integralmente à organização e nela se profissionalizam, seguindo uma carreira que os conduz até a posição de político profissional. Esse seria o fator que explicaria a presença maior de políticos profissionais no universo de candidatos dentro do PT.

\section{Tabela 4 - Partidos e Ocupação Profissional dos Candidatos}

\begin{tabular}{|c|c|c|c|}
\hline & \multicolumn{2}{|c|}{ Partido Político } & \multirow[t]{2}{*}{ Total } \\
\hline & PT & PFL & \\
\hline Advogado & $4,50 \%$ & $21,20 \%$ & $10,00 \%$ \\
\hline Bancário e Economiário & $3,00 \%$ & & $2,00 \%$ \\
\hline Comerciante & $3,00 \%$ & & $2,00 \%$ \\
\hline Dona de Casa & $1,50 \%$ & & $1,00 \%$ \\
\hline Empresário & $6,00 \%$ & $15,20 \%$ & $9,00 \%$ \\
\hline Engenheiro & & $9,10 \%$ & $3,00 \%$ \\
\hline Médico & $3,00 \%$ & $3,00 \%$ & $3,00 \%$ \\
\hline Professor de Ensino Superior & $9,00 \%$ & & $6,00 \%$ \\
\hline Sacerdote ou Membro de Odem ou Seita Religiosa & & $3,00 \%$ & $1,00 \%$ \\
\hline Tabelião & & $3,00 \%$ & $1,00 \%$ \\
\hline Artes / Desportos & $4,50 \%$ & & $3,00 \%$ \\
\hline Atividades de Prestação de Serviços & $1,50 \%$ & & $1,00 \%$ \\
\hline Funcionários Públicos & $7,50 \%$ & $6,10 \%$ & $7,00 \%$ \\
\hline Polícia Civil e Polícia Militar & & $3,00 \%$ & $1,00 \%$ \\
\hline Político & $29,90 \%$ & $12,10 \%$ & $24,00 \%$ \\
\hline Produtor Agropecuário & $3,00 \%$ & $15,20 \%$ & $7,00 \%$ \\
\hline Trabalhadores Assalariados Urbanos & $1,50 \%$ & $6,10 \%$ & $3,00 \%$ \\
\hline Trabalhadores da área de Comunicação & & $3,00 \%$ & $1,00 \%$ \\
\hline Trabalhadores da Educação & $11,90 \%$ & & $8,00 \%$ \\
\hline Trabalhadores do Setor Rural & $4,50 \%$ & & $3,00 \%$ \\
\hline Outros & $6,00 \%$ & $4,00 \%$ & \\
\hline Total & $100,00 \%$ & $100,00 \%$ & $100,00 \%$ \\
\hline
\end{tabular}

Fonte: TSE e NUSP

\footnotetext{
${ }^{17}$ Um procedimento mais inclusivo na escolha dos candidatos não significa que o procedimento seja menos controlado pelo partido.

O ReCRUtAMENTO POLÍtico no PT E No PFL PARANAENSES NAS ELEIÇões ... 
Vejamos a seguir como se configura, a partir das mesmas variáveis, o universo dos candidatos vitoriosos no PT e no PFL.

\section{UM PERFIL SOCIAL DOS ELEITOS DO PT E DO PFL: GÊNERO, OCUPAÇÃO E EDUCAÇÃO ${ }^{18}$}

No universo dos eleitos as características dos dois partidos analisadas permanecem ainda muito similares no que diz respeito ao gênero e ao nível de escolaridade (tabelas 5 e 6). Os eleitos do PT e do PFL são esmagadoramente formados por homens com ensino superior completo. Portanto, nesse caso, o fato de o Partido dos Trabalhadores contar com um estatuto partidário que permite um procedimento um pouco mais inclusivo do que o PFL não parece afetar o resultado final do processo eleitoral.

\section{Tabela 5 - Partido Político e sexo dos eleitos}

\begin{tabular}{lccc}
\hline & Sexo & & Total \\
& Feminino & Masculino & \\
PT & $10 \%$ & $90 \%$ & $100 \%$ \\
\hline PFL & $x$ & $100 \%$ & $100 \%$ \\
& $4,8 \%$ & $95,2 \%$ & $100 \%$ \\
\hline
\end{tabular}

Fonte: TSE e NUSP

Tabela 6 - Partido Político e nível DE ESCOLARIDADE DOS CANDIDATOS

\begin{tabular}{|c|c|c|c|c|c|c|c|}
\hline & \multicolumn{6}{|c|}{ Escolaridade } & \multirow[t]{2}{*}{ Total } \\
\hline & $\begin{array}{c}\text { Ensino } \\
\text { Fundamental } \\
\text { Incompleto }\end{array}$ & $\begin{array}{l}\text { Ensino } \\
\text { Fundamental } \\
\text { Completo }\end{array}$ & $\begin{array}{c}\text { Ensino } \\
\text { Médio } \\
\text { Incompleto }\end{array}$ & $\begin{array}{l}\text { Ensino } \\
\text { Médio } \\
\text { Completo }\end{array}$ & $\begin{array}{c}\text { Ensino } \\
\text { Superior } \\
\text { Incompleto }\end{array}$ & $\begin{array}{l}\text { Ensino } \\
\text { Superior } \\
\text { Completo }\end{array}$ & \\
\hline $\mathrm{PT}$ & $10 \%$ & $x$ & $x$ & $x$ & $20 \%$ & $70 \%$ & $100 \%$ \\
\hline PFL & $x$ & $x$ & $9,1 \%$ & $x$ & $18,20 \%$ & $72,7 \%$ & $100 \%$ \\
\hline Total & $4,8 \%$ & $x$ & $4,8 \%$ & $17 \%$ & $19 \%$ & $71,4 \%$ & $100 \%$ \\
\hline
\end{tabular}

Fonte: TSE e NUSP

\footnotetext{
${ }^{18}$ Neste momento do texto o número de casos se reduz substancialmente de 100 (candidatos) para 21 eleitos, dos quais 10 são do Partido dos Trabalhadores e 11 do PFL.
} 
As diferenças quanto à ocupação, por sua vez, reforçam as nossas considerações feitas sobre o universo dos candidatos dos dois partidos. Como se percebe pelos dados da tabela 7, o PT recruta seus eleitos majoritariamente entre aqueles que se declararam como políticos, ficando o restante com os professores universitários. 0 recrutamento do PFL é, nesse sentido, bem mais inclusivo, ainda que também seja um tanto concentrado, no caso, entre os profissionais liberais (advogados, engenheiros e médicos, perfazendo cinco indivíduos em onze) e entre proprietários (empresários e produtores agropecuários, numa proporção de três em onze). Evidentemente, a comparação quanto à inclusividade social dos dois partidos fica, neste momento do texto, comprometida porque não temos como saber a ocupação prévia daqueles que se declararam políticos ${ }^{19}$.

\begin{tabular}{lccc} 
TABELA 7 - PARTIDO E PROFISSÕES ENTRE ELEITOS \\
\hline & Partido Político & \\
\hline & $\mathrm{PT}$ & $\mathrm{PFL}$ & Total \\
\hline Advogado & $\mathrm{x}$ & $9,10 \%$ & $4,80 \%$ \\
\hline Empresário & $\mathrm{x}$ & $18,20 \%$ & $9,50 \%$ \\
\hline Engenheiro & $\mathrm{x}$ & $9,10 \%$ & $4,80 \%$ \\
\hline Médico & $20 \%$ & $\mathrm{x}$ & $9,50 \%$ \\
\hline Professor de Ensino Superior & $70 \%$ & $18,20 \%$ & $42,90 \%$ \\
\hline Político & $10 \%$ & $18,20 \%$ & $14,30 \%$ \\
\hline Produtor Agropecuário & $\mathrm{x}$ & $9,10 \%$ & $4,80 \%$ \\
\hline Trabalhadores Assalariados Urbanos & $100 \%$ & $100 \%$ & $100 \%$ \\
\hline Total & & & \\
\hline
\end{tabular}

Fonte: TSE e NUSP

\footnotetext{
${ }^{19}$ Veremos mais adiante, quando analisarmos o perfil social dos eleitos, que a maior inclusividade do PFL é apenas aparente.
} 


\section{GÊNERO, ESCOLARIDADE, OCUPAÇÃO E AS CHANCES DE SUCESSO ELEITORAL}

Do ponto de vista do desenho da pesquisa que originou este artigo, o ideal seria saber em que medida o caráter mais ou menos inclusivo do estatuto afetaria 0 universo dos candidatos e dos eleitos. No entanto, para o universo dos candidatos só faria sentido colocar essa questão se pudéssemos comparar o perfil daqueles aspirantes que foram bem sucedidos, isto é, que se transformaram efetivamente em candidatos, com aqueles que fracassaram ${ }^{20}$. No que diz respeito ao universo dos eleitos, a questão não faz sentido, pois os estatutos partidários têm o mesmo valor para todos os que saíram vitoriosos da disputa eleitoral ${ }^{21}$. Por essas razões, resolvemos nos perguntar em que medida algumas variáveis aqui analisadas gênero, ocupação e escolaridade - afetam as chances de um indivíduo ser bem sucedido na disputa eleitoral. Em seguida, fizemos essa mesma questão para os dois partidos analisados. A partir dos dados, fizemos algumas considerações sobre 0 grau de inclusão dos dois partidos.

A fim de medir o impacto de algumas variáveis, fizemos um modelo de regressão logística binária, transformando todas as variáveis independentes (sexo, escolaridade e ocupação) em variáveis binárias a fim de testar seu impacto sobre a variável dependente (também binária) ${ }^{22}$.

${ }^{20}$ Suponhamos, por exemplo, que o partido "y" tenha um estatuto altamente excludente; suponhamos ainda que a lista de candidatos desse partido conte com cem nomes oriundos de um estrato social muito restrito, formando, assim, um grupo bastante homogêneo. Poderíamos concluir a partir desses dois fatos que as características do grupo de candidatos se explicam pelas características do estatuto do partido "y"? Não, ao menos tão diretamente. Suponhamos, por fim, que apenas cem pessoas (as mesmas cem escolhidas) tivessem pleiteado uma vaga de candidato. Nesse caso, nenhuma exclusão (e, portanto, nenhuma seleção) teria ocorrido. 0 exemplo não é tão absurdo quanto parece ser quando sabemos que alguns grupos sequer almejam participar da política (fato este que demanda explicação) e que alguns partidos sequer conseguem completar a sua lista de candidatos.

${ }^{21} 0$ que, é claro, não quer dizer que somente os eleitores tenham o poder de definir a sorte dos candidatos. 0 maior ou menor apoio do partido a uma candidatura pode fazer toda a diferença para as pretensões eleitorais de um indivíduo. No entanto, este é um fato que não pode ser captado por uma análise dos estatutos partidários.

${ }^{22}$ A regressão logística é uma ferramenta de análise estatística útil nos casos em que se pretende predizer ou explicar a presença ou ausência de determinada característica a partir dos valores de um conjunto de medidas preditoras. Nesse sentido, é similar aos modelos de regressão linear, porém pode ser aplicado nas situações em que a variável dependente é dicotômica. As variáveis 


\begin{tabular}{lc}
\hline \multicolumn{1}{c}{ Variáveis } & Odds ratio \\
\hline Político profissional & $3,259^{*}$ \\
Alta escolaridade & $4,827^{* *}$ \\
Sexo (masculino) & $3,495^{* *}$ \\
${ }^{*} \mathrm{p}=0,032^{* *} \mathrm{p}>0,05$ & \\
\hline
\end{tabular}

0 que se percebe pelos dados acima é que nem escolaridade nem sexo afetam as chances de sucesso eleitoral, pois o resultado do modelo para essas duas variáveis não foi significativo. De fato, a maior parte dos estudos sobre recrutamento de elites políticas tem mostrado que o filtro que impede a entrada de mulheres e pessoas portadoras de baixa escolaridade não opera dentro dos partidos políticos (RANNEY, 1965; GALLAGHER E MARSH, 1988; NORRIS e LOVENDUSKI, 1995; CAMP, 1995; NORRIS, 1997; FREIRE, 2001; ÁLVARES, 2006; HTUN E POWER, 2006; BRAGA, 2006; ARAÚJ0 e ALVES, 2007; BRAGA e PRAÇA, 2007; ÁLVARES, 2007; VEIGA E MIRÍADE, 2007). Ao contrário, esse filtro é de natureza "social". Muito provavelmente, as mulheres e as pessoas com baixo grau de instrução formal se "auto-excluem" da vida política em função da falta de recursos necessários para o exercício desta atividade (NORRIS, 1995, p. 152-155; 1997, p. 211-212). No caso das mulheres, falta-lhes um dos mais importantes recursos políticos que é 0 tempo (NORRIS, 1995, p. 158). No caso dos desprovidos de escolaridade, falta-lhes a intimidade com a língua culta e a ausência de um capital (o capital cultural) socialmente legítimo.

Por essa razão, uma comparação entre 0 universo dos candidatos e 0 universo dos que conseguem se eleger revela grande proximidade quando vistos à luz dessas duas variáveis (gênero e escolaridade). Em geral, o baixo percentual de mulheres que decide se candidatar se repete no universo de eleitos, ocorrendo o mesmo com os possuidores de um baixo capital escolar. Em função disso, essas duas variáveis não revelam impacto significativo no universo dos eleitos e a ausência desse impacto sugere que não é o partido o locus onde se realiza a

independentes ou preditoras podem ser intervalares ou categóricas, sendo que nesse último caso devem ser codificadas como medidas indicadoras ou dummy. Nesse artigo, os coeficientes obtidos com os modelos propostos são usados como estimativas das razões de chance (estimate odds ratios) para cada uma das variáveis independentes introduzidas no modelo. Cf. Powers e Xie (2000). Lembramos ainda que um universo seguro para inferência estaria em torno de 100 indivíduos, como é o $\mathrm{N}$ de candidatos que estamos aqui trabalhando. 
exclusão desses grupos.

Ao contrário, o peso do "político profissional" é bem maior. Somente para esta variável o modelo produziu resultados estaticamente significativos. Como se percebe, a condição de político profissional aumenta em mais de três vezes as chances de um candidato sair vitorioso da disputa eleitoral ${ }^{23}$. Esse dado revela que ter um capital político prévio, para os casos em questão, é mais importante do que possuir os atributos anteriormente analisados.

Evidentemente, isso não quer dizer que a posse de determinados atributos sociais não sejam importante para entrar na política. Como dissemos acima, esses atributos são importantes, mas parecem operar como filtros sobretudo fora dos partidos. No entanto, uma vez dentro da organização partidária, é o fato de ter experiência política prévia que pesa mais para determinar o sucesso eleitoral do indivíduo.

Como se apresentariam esses dados quando analisados nos dois partidos? Os resultados podem ser vistos abaixo ${ }^{24}$.

\begin{tabular}{cc}
\hline Variáveis & Odds ratio \\
\hline PT & \\
\hline Político profissional & $6,908^{*}$ \\
\hline Alta escolaridade & $4,063^{* *}$ \\
\hline Sexo (masculino) & $1,156^{* *}$ \\
\hline PFL & \\
\hline Político profissional & $5,872^{* *}$ \\
\hline Alta escolaridade & $4,831^{* *}$ \\
\hline Sexo (masculino) & $10,180^{* *}$ \\
\hline${ }^{*} \mathrm{p}=0,012 \quad{ }^{* *} \mathrm{p}>0,05$ & \\
\hline
\end{tabular}

Como podemos perceber pelas informações fornecidas pelo output do nosso modelo de regressão, o único resultado significativo refere-se ao impacto que ser político profissional representa para que um candidato do Partido

\footnotetext{
${ }^{23}$ Para traduzir esses números em porcentagem, podemos realizar o seguinte procedimento: $(3,259-1) \cdot 100=225,9 \%$. Ou seja, ser deputado eleva em $226 \%$ a chance de ser eleito.

${ }^{24}$ Aqui estamos trabalhando com um $\mathrm{N}$ reduzido, devido à separação entre os dois partidos. Isso deve ser levado em conta no momento da interpretação dos dados.
} 
dos Trabalhadores consiga ser eleito. Esse resultado não se repete no caso dos candidatos a deputado estadual e federal do Partido da Frente Liberal. Nesse sentido, acreditamos serem pertinentes as mesmas afirmações feitas acima quanto às características específicas do Partido dos Trabalhadores.

0 quadro 1 (anexo) nos fornece algumas informações interessantes a respeito. Os eleitos do PT vêm de estratos sociais situados bem abaixo daqueles em que se originam os políticos do PFL. Isso se revela não apenas pela profissão prévia que exerciam antes de assumirem um cargo eletivo pela primeira vez, mas também pelo tipo de engajamento que os caracteriza. Enquanto os eleitos do PT atuam predominantemente nos sindicatos dos trabalhadores, no PFL encontramos indivíduos que atuam em sindicatos patronais, em empresas estatais ou são oriundos de família com tradição política ou com inserção prévia no aparelho de Estado. Apesar dessa diferença, vale observar a existência de algo em comum entre os dois partidos: em ambos encontramos quatro deputados filiados às camadas médias profissionalizadas, notadamente médicos e professores universitários.

No entanto, o dado mais interessante que esse quadro nos revela é que os eleitos do PT têm o que poderíamos chamar de uma "carreira partidária" antes de ocuparem o seu primeiro cargo eletivo. Em média, os militantes do PT que compõem o presente quadro dedicam-se 9,6 anos à organização partidária para, só então, assumir um cargo político. Além disso, jamais se filiaram a outro partido. Nesse sentido, o PT pode ser mais inclusivo no sentido de permitir uma participação mais ampla de seus membros na escolha dos candidatos e por realizar um recrutamento em estratos sociais mais representativos da população como um todo, mas isso não o impede de ser uma organização bastante estruturada a ponto de, como dissemos, exigir dos seus membros uma longa dedicação ao partido antes de obter o direito de disputar um cargo eletivo.

No caso do PFL, não é sequer possível identificar a média de anos dedicados ao partido antes do primeiro cargo, porque a grande maioria dos seus eleitos se filiou ao partido já sendo um político profissional. Observe-se ainda que, no caso do PT, para os indivíduos em questão, faz parte dessa "carreira partidária" assumir cargos de direção no interior da organização. Para o PFL quase não se encontra informação a respeito, o que é um indicativo da pouca importância do partido para a biografia dos seus membros.

Nesse sentido, é plausível dizer, a partir das contribuições de Panebianco (2005) e Meneguello (1989), que o PT é um partido é bem estruturado em função 
do fato de ser ele uma fonte essencial de recursos políticos para os seus membros. A possibilidade de ascender na carreira política está intimamente ligada aos recursos materiais, políticos e simbólicos que eles podem obter no interior da organização e somente aí. Ao contrário, os eleitos pelo PFL já dispõe de recursos estratégicos para a vida política muito antes de terem se integrado a essa agremiação. São pessoas com dinheiro, patrimônio e capital social. Alguns deles vêm de famílias com tradição política e outros circulam pelas "altas rodas" do Estado e do mundo patronal antes de entrarem na vida política. Nessas condições, filiar-se a um partido pode ser apenas uma formalidade a ser cumprida em função das exigências legais.

É de se esperar que um recrutamento tão diferenciado produza comportamentos políticos também distintos. Nesse caso, podemos utilizar a tipologia elaborada por Siavelis e Morgenstern (2004, p. 9-10). Para esses autores, a natureza do processo de recrutamento e seleção gera tipos de candidatos que, uma vez eleitos, adotam comportamentos que podem afetar significativamente 0 funcionamento das instituições políticas. Os tipos ideais de candidatos produzidos pelos processos de recrutamento e seleção nos diferentes partidos na América Latina seriam os seguintes: oparty loyalist, o constituent servant, o group delegate e 0 entrepreneur. 0 critério que permite aos autores elaborar essa tipologia refere-se às relações de lealdade que um determinado processo de recrutamento estabelece, que, por sua vez, constrangeriam o comportamento do político uma vez no cargo.

Seria importante um estudo mais aprofundado dos dois partidos para testar a tipologia desses autores. No entanto, de saída, dizemos que é preciso ter uma compreensão mais ampla do que seja "comportamento político". A ciência política brasileira tem mostrado que estritamente no âmbito do processo decisório legislativo, os políticos brasileiros (inclusive dos dois partidos aqui analisados) são "fiéis" à orientação de suas lideranças partidárias. Mas tal "fidelidade" constituise numa obediência interessada, já que os liderados receiam as retaliações que um comportamento "infiel" poderia produzir e as consequiências negativas disso para as suas carreiras políticas (Fugueiredo e Limongi 1999). Parece-nos, entretanto, que essa "fidelidade" descreve muito mais uma relação de poder do que de autoridade e que, portanto, desapareceria em situações nas quais as ameaças de sanções fossem suspensas ou se mostrassem ineficazes ${ }^{25}$.

Porém, se tivermos uma compreensão mais ampla do comportamento

\footnotetext{
${ }^{25}$ Fizemos uma crítica mais aprofundada desse modo de compreender a fidelidade partidária em Perissinotto (2004).
} 
político, talvez possamos analisar melhor o impacto do tipo de recrutamento sobre a atuação dos políticos profissionais nos moldes sugeridos por Siavelis e Morgenstern. Nesse sentido, poderíamos ver em que medida a estratégia de campanha eleitoral é mais ou menos ancorada no partido, se o candidato recorre mais aos recursos extra ou intra-partidários, se no processo decisório legislativo ele acompanha as indicações dos líderes mesmo na ausência de eventuais sanções, se ele se preocupa em formular propostas de políticas públicas de acordo com 0 conteúdo programático do partido e assim por diante. Seja como for, os estudos de recrutamento político devem, para se justificar ainda mais, levar a estudos de comportamento.

\section{UMA CONCLUSÃO À GUISA DE REFLEX̃̃O}

As observações feitas anteriormente nos permitem concluir o presente artigo com as seguintes considerações:

1) Os estudos de elite precisam fazer análises de recrutamento no sentido amplo, isto é, uma análise dos processos de "filtragem" que acabam por produzir um grupo de vitoriosos ("os que chegaram lá”) com características específicas e não aleatórias. Além disso, é preciso desenvolver estudos que mostram como essas características afetam o comportamento dos "escolhidos".

2) No que diz respeito exclusivamente ao que foi analisado acima, parece que a exclusão de mulheres e pessoas com baixa escolaridade ocorre fora dos partidos políticos, já que esses dois grupos reproduzem o percentual de sua presença entre os candidatos no universo dos eleitos. Nesse sentido, 0 analista deve olhar para as relações sociais mais amplas, fora das organizações partidárias, para tentar entender a baixa presença desses indivíduos na vida política.

3) Não temos como dizer se o perfil socialmente mais inclusivo (dos candidatos e dos eleitos), no caso do Partido dos Trabalhadores, deve-se ao seu estatuto também mais inclusivo. Quanto a esse ponto, talvez seja mais plausível atribuir essa maior inclusividade social à gênese do partido e à sua história de vínculo com os movimentos sociais. De resto, não nos parece teoricamente impossível pensar em um partido com um estatuto mais "participativo" que, ao mesmo tempo, produza um universo de candidatos e eleitos socialmente homogêneo e fechado. Quanto a este ponto vale lembrar que os estatutos partidários não produzem qualquer diferença no que diz respeito ao gênero e ao 
nível de escolaridade dos candidatos e dos eleitos dos dois partidos analisados.

4) A análise qualitativa dos dados relativos aos eleitos revela, no caso do PT, um elenco de ocupações bem mais modesto (e bem mais inclusivo, se comparada com a população economicamente ativa). Esse fator talvez explique a intensa profissionalização política dos eleitos por este partido.

Enfim, se a análise da inclusividade dos estatutos partidários, para o caso em questão, é importante para caracterizar o tipo de procedimento interno que permite escolher um universo específico de candidatos, a partir do qual se formará um universo específico de eleitos, parece-nos importante também olhar para outras dimensões (social e histórica, por exemplo) para entender mais adequadamente 0 perfil dos que se envolvem em política e, por fim, o comportamento político desses indivíduos.

\section{REFERÊNCIAS}

ÁLVARES, Maria Luzia. Determinantes da seleção de candidaturas aos cargos parlamentares e regras estatutárias na formação do selecionador brasileiro, nas eleições de 2002. Belo Horizonte: Paper no $5^{\circ}$ Encontro da ABCP, 2006.

. Formação de Elites \& Seleção de Candidaturas: o "jardim secreto" da elaboração de listas partidárias. Caxambu: Paper no XXXI Encontro Anual da ANPOCS,2007.

ARAÚJO, Clara \& ALVES, José Eustáquio D. Impactos de Indicadores Sociais e do Sistema Eleitoral sobre As Chances das Mulheres nas Eleições e suas Interações com as Cotas. Rio de Janeiro: DADOS - Revista de Ciências Sociais. Vol. 50, n. 3, 2007.

BILAC, Maria B. As Elites Políticas de Rio Claro. Recrutamento e Trajetória. Piracicaba/Campinas: Editora Unimep/Editora da Unicamp, 2001.

BRAGA, Sérgio S. Quem foi quem na Assembléia Constituinte de 1946: um perfil socioeconômico e regional da Constituinte de 1946. Brasília: Câmara dos Deputados, Coordenação de Publicações, 1998.

BRAGA, Maria do Socorro. Recrutamento Partidário e Representação: seleção de candidatos à Câmara dos Deputados do Brasil. Campinas: Paper no III Congresso Latino Americano de Ciência Política. Democracia e Desigualdades, 2006. 
Partidos Políticos: organização e controle sobre a dinâmica de representação na democracia brasileira. Belo Horizonte: Paper no V Encontro da Associação Brasileira de Ciência Política. 2006.

BRAGA, Maria do Socorro \& PRAÇA, Sergio. Recrutamento partidário: seleção de candidatos à Câmara paulistana. In: KINZO, Maria D’Alva, \& BRAGA, Maria do Socorro (Orgs.), Eleitores e representação partidária no Brasil (pp. 179-204). São Paulo: Associação Editorial Humanitas, 2007.

CAMP, Roderic Ai. Political Recruitment across Two Centuries. Mexico, 1884-1991. Austin: University of Texas Press, 1995.

FIGUEIRED0, Argelina C. e LIMONGI, Fernando P. Executivo e Legislativo na nova ordem Constitucional. Rio de Janeiro: Editora FGV, 1999.

FLEISCHER, David Verge. O Pluripartidarismo no Brasil: dimensões sócioeconômicas e regionais do recrutamento legislativo, 1946-1967. Revista de Ciência Política , 24 (1), 1981.

FREIRE, André (Org.). Recrutamento Parlamentar. Os Deputados Portugueses da Constituinte à VII Legislatura. Lisboa: STAPE - Secretariado Técnico dos Assuntos para o Processo Eleitoral, 2001.

GALLAGHER, Michael, \& MARSH, Michael. Candidate Selection in Comparative Perspective. The Secret garden of Politics. London: SAGE Publications, 1988.

GIDDENS, Anthony. Preface. Elites in the British Class Structure. In: STANWORTH, Philip \& GIDDENS, Anthony. Elites and Power in British Society. Cambridge: Cambridge University Press, 1974.

GRILL, Igor. G. Processos, condicionantes e bases sociais da especialização política no Rio Grande do Sul e no Maranhão. Caxambu: Paper no XXXI Anual da ANPOCS, 2007.

HAZAN, Reuven Y. Candidate Selection. In: L. Niemi, R. Gunter, \& P. Norris, Comparing Democracies 2. London, Thousand Oaks, New Delhi: SAGE Publications, 2002.

HTUN, Mala; POWER, Timothy J. Gender, Parties, and Support for Equal Rights in the Brazilian Congress. Latin American Politics and Society. Vol. 48, n 4, 2006. LOVE, Joseph. A Locomotiva. São Paulo na Federação Brasileira 1889-1937. Rio de Janeiro: Paz e Terra, 1982.

LOVE, Joseph., \& BARICKMAN, Bert. Regional Elites. In: CONIFF, Michael \& 
McCANN,Frank D. Modern Brazil: Elites and Masses in Historical Perspective. Lincoln: University of Nebraska Pres, 1991.

MARENCO DOS SANTOS, André. Nas Fronteiras do Campo Político. Raposas e outsiders no Congresso Nacional. RBCS , 12 (33), 1997.

MARENCO DOS SANTOS, André \& SERNA, Miguel. Por que carreiras políticas na esquerda e na direita não são iguais? Recrutamento legislativo no Brasil, Chile e Uruguai. Revista Brasileira de Ciências Sociais. Vol. 22, n. 64. 2007.

MENEGUELLO, Rachel. PT: A Formação de um Partido. 1979-1982. Rio de Janeiro: Paz e Terra, 1989.

MESSENBERG, Debora. A Elite Parlamentar do Pós-Constituinte: Atores e Práticas. São Paulo: Brasiliense, 2002.

MICELI, Sergio. Carne e Osso da Elite Política Brasileira Pós-1930. In: Fausto, Boris. História Geral da Civilização Brasileira (6ª ed., Vol. Tomo III). São Paulo: Bertrand Brasil, 1981.

MICHELS, Robert. Para Uma Sociologia dos Partidos Politicos na Democracia Moderna. Lisboa: Antígona, 2001.

MOSCA, Gaetano. La Clase Politica. México: Fondo de Cultura Económica, 1984.

NORRIS, Pipa. Passages to Power. Legislative recruitment in advanced democracies. Cambridge: Cambridge University Press, 1997.

NORRIS, Pipa e LOVENDUSKI, Joni. Political Recruitment. Gender, Race and Class in the British Parliament. Cambridge: Cambridge University Press, 1995.

NUNES, Edson 0. Legislativo, Política e Recrutamento de Elites no Brasil. DADOS, 17, 1978.

PANEBIANCO, Angelo. Modelos de Partido. Organização e poder nos partidos políticos. São Paulo: Martins Fontes, 2005.

PARTIDO DOS TRABALHADORES. Estatuto do PT, 2001.

PARTIDO DA FRENTE LIBERAL. Estatuto do PFL.

PERISSINOTTO, Renato M. Poder e Participação no Conselho Municipal de Assistência Social de Curitiba (1999-2001). In: FUKS, Mario; PERISSINOTTO, Renato M.; SOUZA, Nelson R. (Orgs.). Democracia e Participação: os conselhos gestores do Paraná. Curitiba: Editora da UFPR, 2004.

POWER, Timothy \& MOCHEL, Marilia. G. Shaping the Brazilian Political Class: 
Causes and Consequences of Recruitment to the Chamber of Deputies. Paper no evento Pathways to Power: Political Recruitment and Democracy in Latin America. Winston-Salem: Wake Forest University, 2004.

PUTNAM, Robert. D. The Comparative Study of Political Elites. Englewood Cliffs: Prentice Hall, 1976.

RAHAT, Gideon \& HAZAN, Reuven Y. Candidate Selection Methods: An Analytical Framework. Party Politics , 7 (33), 2001.

RANNEY, Austin. Pathways to Parliament. Madison and Milwaukee: The University of Wisconsin Press, 1965.

SAMUELS, David. Political Ambition, Candidate Recruitment and Legislative Politics in Brazil. Paper no evento Pathways to Power: Political Recruitment and Democracy in Latin America. Winston-Salem: Wake Forest University, 2004.

SANTOS, Fabiano. Deputados Federais e Instituições Legislativas no Brasil: 1946-1999. In: BOSCHI, Renato; DINIZ, Eli \& SANTOS, Fabiano. (orgs.). Elites Políticas e Econômicas no Brasil Contemporâneo. São Paulo: Fundação Konrad Adenauer, 2000.

SIAVELIS, Peter M., \& MORGENSTERN, Scott. Political Recruitment and Candidate Selection in Latin America. A Framework for Analysis. Paper na Pathways to Power: Political Recruitment and Democracy in Latin America. WinstonSalem: Wake Forest University, 2004.

VEIGA, Luciana F. \& MIRÍADE, Angel. Perfil dos Candidatos e eleitos na disputa partidária para a Câmara dos Deputados em 2006. Paper no VI Encontro Internacional do FOMERCO. Aracaju, 2007. 


\section{ANEXO - DADOS SOBRE OS CANDIDATOS ELEITOS POR PARTIDOS POLÍticos (PT E PFL) ${ }^{26}$}

\begin{tabular}{|c|c|c|c|c|c|c|c|c|}
\hline $\begin{array}{l}\text { Deputados } \\
\text { do PT }\end{array}$ & $\begin{array}{l}\text { Profissão } \\
\text { anterior }\end{array}$ & $\begin{array}{l}\text { Ano de } \\
\text { filiação }\end{array}$ & $\begin{array}{l}\text { Engajamento } \\
\text { prévio }\end{array}$ & $\begin{array}{l}\text { Primeiro } \\
\text { cargo }\end{array}$ & $\begin{array}{l}\text { Ano do } \\
\text { primeiro } \\
\text { cargo }\end{array}$ & $\begin{array}{l}\text { Atividades } \\
\text { partidárias }\end{array}$ & $\begin{array}{c}\text { Tempo entre } \\
\text { filiação e } \\
\text { primeiro } \\
\text { cargo }\end{array}$ & $\begin{array}{l}\text { Outro } \\
\text { partido }\end{array}$ \\
\hline $\begin{array}{l}\text { Tadeu } \\
\text { Veneri }\end{array}$ & Bancário & 1988 & $\begin{array}{l}\text { Sindicato dos } \\
\text { bancários }\end{array}$ & Vereador & 1995 & $\begin{array}{l}\text { Direção } \\
\text { Nacional }\end{array}$ & 7 & não \\
\hline $\begin{array}{l}\text { Enio José } \\
\text { Verri }\end{array}$ & $\begin{array}{l}\text { Professor } \\
\text { universitário }\end{array}$ & 1985 & $\begin{array}{l}\text { Militância } \\
\text { partidária }\end{array}$ & $\begin{array}{l}\text { Secre- } \\
\text { tário de } \\
\text { governo }\end{array}$ & 2001 & $\begin{array}{l}\text { Diretório } \\
\text { estadual }\end{array}$ & 16 & não \\
\hline $\begin{array}{l}\text { Péricles } \\
\text { de Mello }\end{array}$ & $\begin{array}{c}\text { Professor } \\
\text { Universitário }\end{array}$ & 1980 & $\begin{array}{l}\text { Movimento } \\
\text { estudantil }\end{array}$ & Vereador & 1988 & $\begin{array}{l}\text { Diretório } \\
\text { estadual }\end{array}$ & 8 & não \\
\hline $\begin{array}{l}\text { Elton } \\
\text { Weter }\end{array}$ & $\begin{array}{l}\text { Pequeno } \\
\text { agricultor }\end{array}$ & 1993 & $\begin{array}{c}\text { Assessor } \\
\text { parlamentar }\end{array}$ & Vereador & 1997 & $\begin{array}{c}\text { Comissão } \\
\text { Executiva } \\
\text { Estadual }\end{array}$ & 4 & não \\
\hline $\begin{array}{l}\text { Luciana } \\
\text { Rafagnin }\end{array}$ & $\begin{array}{l}\text { Pequeno } \\
\text { Agricultor }\end{array}$ & 1989 & $\begin{array}{c}\text { Sindicato } \\
\text { trabalhadores } \\
\text { rurais }\end{array}$ & Vereador & 1992 & $\begin{array}{c}\text { Comissão } \\
\text { Executiva } \\
\text { Estadual }\end{array}$ & 3 & não \\
\hline Pedro Ivo & Agricultor & 1986 & $\begin{array}{c}\text { Comunidades } \\
\text { Eclesiais de } \\
\text { Base }\end{array}$ & Prefeito & 1996 & $\begin{array}{l}\text { Fundador } \\
\text { do PT no } \\
\text { sul do } \\
\text { estado }\end{array}$ & 10 & não \\
\hline $\begin{array}{l}\text { Assis } \\
\text { Couto }\end{array}$ & $\begin{array}{l}\text { Pequeno } \\
\text { Agricultor }\end{array}$ & 1987 & $\begin{array}{l}\text { Sindicato } \\
\text { Trabalhado- } \\
\text { res rurais }\end{array}$ & $\begin{array}{l}\text { Depu- } \\
\text { tado } \\
\text { Federal }\end{array}$ & 2006 & $\begin{array}{l}\text { Diretório } \\
\text { municipal }\end{array}$ & 19 & não \\
\hline $\begin{array}{l}\text { André } \\
\text { Vargas }\end{array}$ & $\begin{array}{l}\text { Cargos de } \\
\text { confiança no } \\
\text { setor público }\end{array}$ & 1988 & $\begin{array}{l}\text { Entidades } \\
\text { sociais benefi- } \\
\text { cientes }\end{array}$ & Vereador & 2001 & $\begin{array}{l}\text { Presi- } \\
\text { dente } \\
\text { estadual }\end{array}$ & 13 & não \\
\hline $\begin{array}{l}\text { Angelo } \\
\text { Vanhoni }\end{array}$ & Bancário & 1981 & $\begin{array}{l}\text { Sindicato dos } \\
\text { bancários }\end{array}$ & Vereador & 1989 & $\begin{array}{l}\text { Diretório } \\
\text { estadual }\end{array}$ & 8 & não \\
\hline $\begin{array}{l}\text { Florisvaldo } \\
\text { Fier }\end{array}$ & $\begin{array}{l}\text { Médico no } \\
\text { setor público }\end{array}$ & 1981 & $\begin{array}{l}\text { Sindicalismo } \\
\text { do setor } \\
\text { público e } \\
\text { representação } \\
\text { profissional }\end{array}$ & Vereador & 1989 & $\begin{array}{c}\text { Comissão } \\
\text { Executiva } \\
\text { Estadual }\end{array}$ & 8 & não \\
\hline $\begin{array}{l}\text { Deputados } \\
\text { do PFL }\end{array}$ & $\begin{array}{c}\text { Profissão } \\
\text { anterior }\end{array}$ & $\begin{array}{l}\text { Ano de } \\
\text { filiação }\end{array}$ & $\begin{array}{l}\text { Engajamento } \\
\text { prévio }\end{array}$ & $\begin{array}{l}\text { Primeiro } \\
\text { cargo }\end{array}$ & $\begin{array}{l}\text { Ano do } \\
\text { primeiro } \\
\text { cargo }\end{array}$ & $\begin{array}{l}\text { Atividades } \\
\text { partidá- } \\
\text { rias }\end{array}$ & $\begin{array}{c}\text { Tempo entre } \\
\text { filiação e } \\
\text { primeiro } \\
\text { cargo }\end{array}$ & $\begin{array}{l}\text { Outro } \\
\text { partido }\end{array}$ \\
\hline $\begin{array}{l}\text { Osmar } \\
\text { Bertoldi }\end{array}$ & Empresário & $\begin{array}{l}\text { Sem } \\
\text { informa- } \\
\text { ção }\end{array}$ & $\begin{array}{l}\text { Sem infor- } \\
\text { mação }\end{array}$ & Vereador & 1992 & $\begin{array}{l}\text { Sem infor- } \\
\text { mação }\end{array}$ & $\begin{array}{l}\text { Sem infor- } \\
\text { mação }\end{array}$ & $\begin{array}{l}\text { Sem } \\
\text { infor- } \\
\text { mação }\end{array}$ \\
\hline $\begin{array}{l}\text { Fábio } \\
\text { Camargo }\end{array}$ & $\begin{array}{c}\text { Cargos de } \\
\text { confiança no } \\
\text { setor público }\end{array}$ & 2004 & $\begin{array}{l}\text { Assessoria } \\
\text { jurídica e } \\
\text { política, com } \\
\text { contatos } \\
\text { familares } \\
\text { no TJ-PR e } \\
\text { no governo } \\
\text { estadual }\end{array}$ & Vereador & 2000 & $\begin{array}{l}\text { Sem infor- } \\
\text { mação }\end{array}$ & $\begin{array}{c}\text { Filiação } \\
\text { posterior } \\
\text { ao primeiro } \\
\text { cargo }\end{array}$ & $\begin{array}{l}\text { PSC e } \\
\text { PTB }\end{array}$ \\
\hline $\begin{array}{l}\text { Durval } \\
\text { Amaral }\end{array}$ & $\begin{array}{c}\text { Advogado } \\
\text { e professor } \\
\text { universitário }\end{array}$ & 1988 & $\begin{array}{l}\text { Movimento } \\
\text { estudantil }\end{array}$ & Vereador & 1982 & $\begin{array}{l}\text { Sem infor- } \\
\text { mação }\end{array}$ & $\begin{array}{c}\text { Filiação } \\
\text { posterior } \\
\text { ao primeiro } \\
\text { cargo }\end{array}$ & PMDB \\
\hline
\end{tabular}

${ }^{26}$ As informações sintetizadas nesse quadro foram retiradas dos sites da Assembléia Legislativa do Paraná (http://www.alep.pr.gov.br/deputados.php), da Câmara dos Deputados (http:// www2.camara.gov.br/) e, quando foi possível, de sítios pessoais dos políticos analisados. 


\begin{tabular}{|c|c|c|c|c|c|c|c|c|}
\hline $\begin{array}{l}\text { Plauto } \\
\text { Miró }\end{array}$ & $\begin{array}{l}\text { Grande } \\
\text { empresário }\end{array}$ & $\begin{array}{l}\text { Sem } \\
\text { informa- } \\
\text { ção }\end{array}$ & $\begin{array}{l}\text { Familia de } \\
\text { políticos } \\
\text { tradicionais } \\
\text { e movimento } \\
\text { estudantil }\end{array}$ & $\begin{array}{l}\text { Depu- } \\
\text { tado } \\
\text { estadual }\end{array}$ & 1991 & $\begin{array}{l}\text { Secretário } \\
\text { geral do } \\
\text { partido no } \\
\text { estado }\end{array}$ & $\begin{array}{c}\text { Filiação } \\
\text { posterior } \\
\text { ao primeiro } \\
\text { cargo }\end{array}$ & PDS \\
\hline $\begin{array}{l}\text { Elio Lino } \\
\text { Rusch }\end{array}$ & $\begin{array}{l}\text { Sem infor- } \\
\text { mação }\end{array}$ & $\begin{array}{l}\text { Sem } \\
\text { informa- } \\
\text { ção }\end{array}$ & $\begin{array}{l}\text { Movimento } \\
\text { estudantil }\end{array}$ & Vereador & 1976 & $\begin{array}{l}\text { Secretário } \\
\text { geral do } \\
\text { partido no } \\
\text { estado }\end{array}$ & $\begin{array}{c}\text { Filiação } \\
\text { posterior } \\
\text { ao primeiro } \\
\text { cargo }\end{array}$ & $\begin{array}{c}\text { Arena, } \\
\text { PDS, } \\
\text { PFL }\end{array}$ \\
\hline $\begin{array}{l}\text { Nelson } \\
\text { Justus }\end{array}$ & $\begin{array}{l}\text { Professor de } \\
\text { Direito }\end{array}$ & 2003 & $\begin{array}{c}\text { Atuação em } \\
\text { empresas } \\
\text { estatais }\end{array}$ & $\begin{array}{l}\text { Depu- } \\
\text { tado } \\
\text { estadual }\end{array}$ & 1991 & $\begin{array}{l}\text { Sem infor- } \\
\text { mação }\end{array}$ & $\begin{array}{c}\text { Filiação } \\
\text { posterior } \\
\text { ao primeiro } \\
\text { cargo }\end{array}$ & РTB \\
\hline $\begin{array}{l}\text { Luiz Car- } \\
\text { los Setim }\end{array}$ & Executivo & 1996 & $\begin{array}{l}\text { Sindicato } \\
\text { Patronal }\end{array}$ & Prefeito & 1997 & $\begin{array}{l}\text { Diretório } \\
\text { municipal }\end{array}$ & 1 & não \\
\hline $\begin{array}{l}\text { Cássio } \\
\text { Taniguchi }\end{array}$ & $\begin{array}{l}\text { Tecnocrata e } \\
\text { empresário }\end{array}$ & 1999 & $\begin{array}{l}\text { Movimento } \\
\text { estudantil, } \\
\text { sindicato } \\
\text { patronal e } \\
\text { associação } \\
\text { profissional }\end{array}$ & Prefeito & 1997 & $\begin{array}{l}\text { Vice-pre- } \\
\text { sidente }\end{array}$ & $\begin{array}{l}\text { Filiação } \\
\text { posterior } \\
\text { ao primeiro } \\
\text { cargo }\end{array}$ & PDT \\
\hline $\begin{array}{l}\text { Eduardo } \\
\text { Sciarra }\end{array}$ & $\begin{array}{c}\text { Empresário } \\
\text { da constru- } \\
\text { ção civil }\end{array}$ & 2001 & $\begin{array}{c}\text { Associações } \\
\text { profissionais } \\
\text { e sindicato } \\
\text { patronal }\end{array}$ & $\begin{array}{l}\text { Depu- } \\
\text { tado } \\
\text { federal }\end{array}$ & 2003 & $\begin{array}{l}\text { Vice-líder } \\
\text { do PFL }\end{array}$ & 2 & PTB \\
\hline $\begin{array}{l}\text { Alceni } \\
\text { Guerra }\end{array}$ & Médico & 1985 & $\begin{array}{c}\text { Associações } \\
\text { profissionais } \\
\text { e sindicato } \\
\text { patronal }\end{array}$ & Prefeito & 1997 & $\begin{array}{l}\text { Presiden- } \\
\text { te do PFL }\end{array}$ & 12 & PDS \\
\hline $\begin{array}{l}\text { Abelardo } \\
\text { Lupion }\end{array}$ & $\begin{array}{l}\text { Agropecu- } \\
\text { arista }\end{array}$ & 1992 & $\begin{array}{l}\text { Família políti- } \\
\text { ca tradicional } \\
\text { eSindicato } \\
\text { Patronal Rural } \\
\quad \text { (UDR) }\end{array}$ & $\begin{array}{l}\text { Depu- } \\
\text { tado } \\
\text { federal }\end{array}$ & 1992 & $\begin{array}{l}\text { Vice-líder } \\
\text { do PFL }\end{array}$ & 0 & PRN \\
\hline
\end{tabular}

